\title{
Our Most Important Creative Task: Interview with Mark Runco
}

\author{
Mark A. Runco \\ Southern Oregon University, USA \\ E-mail address: runcom @sou.edu
}

\author{
Izabela Lebuda \\ University of Wroclaw, Wroclaw, Poland \\ E-mail address: izabela.lebuda@uwr.edu.pl
}

ARTICLE INFO

\section{Keywords:}

Mark Runco

Interview

Creativity

Creativity research

Contrarianism

Divergent thinking

Personal creativity

Article history:

Received 13 December 2020

Received in revised form 16 December 2020

Accepted 16 December 2020

ISSN: 2354-0036

DOI: $10.2478 /$ ctra-2020-0021

\begin{abstract}
A B S TRACT
In the interview with Mark Runco, one of most prolific creativity researchers, we discuss his career, main areas of research interest, chosen research methods and share his thoughts about the future of research on creativity and effectiveness in scientific work.
\end{abstract}

\section{INTRODUCTION}

Mark Runco is Director of Creativity Research and Programming at Southern Oregon University. For many years he was the editor of the Creativity Research Journal. He has published cognitive, economic, genetic, historical, developmental and educational articles and books on the creativity topic. He devised a battery of tests to measures creativity potential and performance. Each year he organizes an international creativity conference. The interview is one of the cycle of structured interviews with creativity researchers who contribute eminently to the contemporary scientific understanding of creativity.

\section{INTERVIEW}

Izabela Lebuda: Please tell me about your professional career; how it happened that among many areas of psychology you took up the psychology of creativity?

Mark Runco: No doubt everyone devoting their careers to the study of creativity has been asked, "why creativity." It would be easy these days to answer that question by list- 
ing all of the benefits of creativity; but my fascination with the topic was not a result of all of its benefits. There is something about the topic that grabbed me as soon as I encountered it as a college sophomore. The topic has not let go, 45 years later.

When I was first introduced to creativity as a subject matter nearly all books and articles were psychological. Fortunately saw great value in psychological research, so it was natural to major in psychology and focus on creativity. My very first interest in psychology was in high school when I heard a lecture on birth order. The model described fit my family perfectly; and of course birth order does relate to creativity.

Even outside of that first psychology class I have long had an interest in cognition. It still amazes me that the reality that each of us experiences is actually not the reality that we encounter in the natural environment. Our cognitive systems must create interpretations, and that's all we really experience: interpretations and coded information. We live in a reality that each of our cognitive systems create. This process of creating reality (or creating each experience) fascinates me independently of the field of creativity. I see the same view of reality in certain philosophies (e.g., Existentialism).

Looking back I am surprised that it took me so long to see that the construction of reality is our most important creative task. This led to the theory of "personal creativity." So early on I was not thinking of the benefits of creativity. Perhaps my value system intuitively recognized the magic and importance of creativity. There certainly wasn't a logic to my decision to study creativity. If personal values contributed, I can blame my family. There is tons of creativity (mostly but not entirely artistic) in my family. Yet I never thought, "my family members are creative and I wonder why? I should study that." That never happened. I simply remember being fascinated by creativity. First it was scientific creativity, but the fascination grew whenever I read something about creativity, in any domain. I mentioned my sophomore year above because my fascination with the topic started with the "Genius and Eminence" class I took as a college sophomore, taught by Robert Albert. He assigned P. E. Vernon's wonderful book, Creativity. It is a collection of chapters, mostly about creative people and the creative process. That volume and Bob Albert's instruction were both a big part of what grabbed me, early on. Looking back at the question I am reminded that it asks about my professional career, and so far I have mostly talked about the early decision to study creativity. Later portions of my career come up as I answer the other questions, below.

Izabela Lebuda: Could you tell the main areas of your research interests and chosen research method in the psychology of creativity? If yes, how did they change over your careers?

Mark Runco: Given what I said in my answer above, my initial reaction to this second question involves creativity as related to families (which are best investigated if you take 
culture into account), but as I studied my interest in creative cognition took over. In part for this reason I was drawn to divergent thinking as a model and kind of assessment. It provides good information about some forms of creative thinking. My introduction to divergent thinking (DT) was Guilford's (1960) chapter in the volume I mentioned above, edited by Vernon; and early in my career I read everything I could find by Guilford. I of course also read the criticism of Guilford, but it seemed to me that those were mostly methodological (he used a subjective factor analytic technique). His conceptualization of DT was useful, independently of his methodology. Many people did not realize this and several times I found myself defending divergent thinking as a meaningful model.

Many people misunderstood the research on divergent thinking. The most common problem seems to follow from the silly assumption that divergent thinking is synonymous with creativity. That makes no sense if you accept the idea of a creativity complex, but apparently many people were disappointed because they were not synonymous. I suppose much the same could be said about the IQ and intelligence. I always refer to test results, including those from tests of divergent thinking, as indicative of creative potential and not indicative of creativity per se. This is because a test is always a sample of behavior, and tests are always imposed and artificial. Some tests do have predictive and ecological validity, but divergent thinking tests must be given correctly (and interpreted correctly, as indicative of potential). There are forms of creative thinking that do not rely on divergent thinking, but DT does provide useful information about creative potential, and when the assessment is done correctly, it is reliable information. Research on DT has helped us to understand creative potential. But DT is just one contribution to creative potential.

My overarching goal for 30 years was to support a science of creativity, which means objectivity is of primary importance, and DT tests offer good objectivity. There are quite a few critics, but when I read them I see that they have not read the original theories and have inappropriate expectations (e.g., DT is synonymous with creative thinking) or use inappropriate methods. An example of inappropriate methods is strict timing of the tests and doing things like that which convey to the examinee that the DT test is like all other tests (e.g. academic exams). DT is likely when it there are game-like conditions. Game- like testing conditions elicit good originality; test-like conditions do not. Many findings about DT in the published research are dubious because the DT tests used in the research were poorly chosen (e.g., maybe one task instead of a variety of DT tasks), poorly administered, or poorly scored. Importantly, computerized scoring methods are working exceptionally well so some of the problems are disappearing. 
Selcuk Acar and I have extended the theory of DT to include "cognitive hyperspace." I have also put quite a bit of time into developing new methodologies (e.g., "ideational pools," "realistic tests of DT, tests of problem finding, socially valid assessments, and most recently an algorithm for determining the creativity of scholarship). Most of the methods developed have been used in the rCAB - a battery of creativity assessments. I did not set out to develop a battery of creativity tests. I did research for decades and often tweaked, adapted, or even introduced new assessment methods. The objective was to better understand creativity using optimally objective methods. Then, about 10 years ago I realized that I had used adapted or developed a pretty good number of tests. An obvious step was to put them all together into one battery (www.creativitytestingservices.com). My goal was research and the tests developed were a means to an ends. The resulting battery of tests was essentially an afterthought. Doing research on creativity has always been tons of fun, especially when it is optimally objective. Recall here what I said above about the overarching goal of my work. The concept of optimal objectivity is discussed below.

Izabela Lebuda: Why do you think it's worth researching creativity?

Mark Runco: I was once on a panel and one of the scholars focused on play. I was to speak about creativity but she went before me. She had all kinds of logic to support her thesis that play is most important topic in the social and behavioral sciences. She may have even said that play was the most important behavior for humans. It was a very broad claim and I was taken aback by it, but she did point to how rules are learned in play and then later translate to all kinds of non-play actions. I mention this experience because I have always known that creativity is of enormous importance for individuals and society, but in the past few years I find myself holding the same extreme view that was held by the play scholar. I now think that there is nothing more important than creativity.

My creativity textbook lists numerous benefits of creativity, and that list grows in each edition. Of course the textbook lists creativity for problem solving (and problem finding), adaptation, innovation, invention, societal and cultural advance, health, and for learning. I follow Piaget on this last point and believe that "to understand is to invent." That is the title of one of his wonderful monographs (Piaget, 1976). I adapted it to title one of my chapters ("to understand is to create") (Runco, 2007). If a person does not invent or create understanding for him- or herself, learning is superficial, a matter of memory alone. Humans must construct meaning - which is part of the reason why I put creativity at the top of my list of important human capacities.

Think how broadly that applies. If authentic meaning must be created, nothing has real meaning unless the individual has created it. Knowledge that is not created for oneself is rote and not very useful. This applies to one's sense of self, to one's understanding 
of the world, and so on. It is a bit like the distinction between information and knowledge. Knowledge must be created for oneself. Long ago I applied this idea to language (following Chomsky's generative grammar) and argued that when language is original and effective, it is the best example we have of everyday creativity. Lately I realized that I was actually thinking too narrowly about creativity and language. I was thinking of language used when an individual creates a meaningful and effective expression that is original (having never been expressed in exactly that way by that individual) and effective (it conveys meaning and can be understood). But what about internal language? The same logic must apply, even though the original result is not shared with others. Internal language must also be created and it provides meaning - to the individual. Now I see meaning as a result of creative thinking both when expressing something via language but also when nothing is expressed to others but meaning for the individual only is the result. This too is a part of personal creativity.

I have also recently followed Jerome Bruner and explored how creativity leads to dignity in life. Bruner said that "there is good reason to inquire about creativity... A reason beyond practicality... The reason is the ancient search of the humanist for excellence... the next creative act may bring [us] to a new dignity" (1962, p. 2). That idea of creativity as more than practical is so important. Recall here what I said above about being drawn to creativity research, not because of the benefits that result from it but more from the intuitive fascination with and magic of the topic.

Interestingly, the dignity that may be associated with creativity has a bridge to the neuroscience of creativity. That is because humans have evolved such that we have an enormous creative capacity. We each have creative potential, apparent in our genes. We can use that potential or waste it. Given that creativity is a part of our genetic make-up, like Bruner I believe that being creative dignifies the actions of the individual. Being creative means that the individual is using rather than wasting what was given. This brief answer may show why my view has changed such that I see creativity as the most important human capacity and activity. Creativity does help us solve problems and innovation, but it also allows us to add meaning to life, to live with dignity. And it certainly adds much to the quality of life.

Izabela Lebuda: What currently do you see the most crucial and most fascinating areas of research on creativity?

Mark Runco: The most crucial area of research is probably that which moves us towards a better understanding of creative potential and its fulfillment. By fulfillment I mean creative potential is no longer latent but is instead translated into actual creative expression. 
We should be able to minimize wasted creative potential if culture, education, politics, families, and businesses all recognize the value of creativity and look to science to identify what must be done to fulfill potential.

The idea of "value" in that sentence is quite significant. So much follows from values. We educate our children, formally and informally, in accordance with cultural and familial values. A parent who values creativity will probably express and appreciate creativity, and children who experience this will internalize the same value system. Values also direct much that goes on in organizations: if an employer or manager explicitly values creativity, the employees are likely to express their creativity. These ideas imply a specific crucial area of research: There is too little research on the role of values in creativity. There was a bit 40 years ago, but not enough now. This should change. Certainly the neurosciences also stand out. They are obviously related to the first point, in the paragraph above, because creative potential is genetic. The neurosciences are especially useful because they will allow us to go beyond mere description of creativity to a point where we should be able to identify the mechanisms underlying creativity and can thus truly and objectively explain it. We will, to quote Skinner, be able to "predict and control." (Control in the scientific sense of being certain we know cause and effect.) I do think that the neurosciences hold much promise but, to put it bluntly, often make mistakes about creativity. The mistakes can be understood using the classic internal vs external control trade-off. The neurosciences are so strong in the former but too often relegate the latter. And given that creativity may require things like spontaneity and intrinsic motivation, and given that these things may be precluded when you get someone in a laboratory, there is a chance that what we are seeing in the neuroscientific research does not generalize well to everyday and authentic creativity. It is a bit like the problem with all tests of creativity. This point was summarized above when tests were described as mere samples of behavior. So, creativity research on potential stands out, as does the related research on values and the neuroscientific research. The answers given below, for the last two questions, also relate to crucial and fascinating research on creativity.

Izabela Lebuda: What do you think, the direction in which the psychology of creativity will develop?

Mark Runco: I must tweak this question, which I know you will allow because creativity researchers respect problem finding and problem redefinition. Therefore I hope I am at liberty to redefine the question and at least start with an answer to, which direction should be avoided?

This question can be answered by looking at how the field has developed in the past few decades. I often wonder what happened! There was a boom about 15-20 years 
after I got started and it has just kept booming. When I did my dissertation on creativity, there was no field of creativity research. There was one journal focused on creativity and it was not rigorous. Boy has that changed. Ironically, I put years into pushing to make creativity research a science. I knew we could be objective about it, especially when I looked at the excellent research being done (e.g., by Simonton, Amabile, Sternberg). Irony is apparent in that now the field is too objective. There is quite a bit of highly controlled research, which is good except the external validity-internal validity trad- off seems to have been forgotten. For that reason some of the most highly controlled research is not really getting at creativity--or at least not at creativity as it occurs in the natural environment, what I think of as "authentic creativity." The lab often precludes the intrinsic motivation, spontaneity, protraction, divergent thinking, and other things that are a part of creativity.

This is one reason I avoid the term "creativity" in my writing. Research often gets at "creative potential," "creative achievement," "creative products," and so on, but we should recognize that there is no one "creativity." Much better to use the adjective, "creative," and thus specify a noun (potential, achievement, products, traits, and so on). In addition to experimental control precluding authentic creative behavior, highly controlled research on creativity very often takes too small a sample of behavior (e.g, one test, or even less - one task) and generalizations to creativity as it occurs in the natural environment are not warranted. To be precise, then, the irony is that for several decades I fought to support a science of creativity, and now I think this has gone too far. Maximal objectivity is not fitting for the research on creativity. I hope one direction research takes is towards an optimal objectivity, so we study actual creative behavior that allows for some of the subjective requirements-some of the feeling and some of the personal, aesthetic, non-rational underpinnings.

There are specific examples of a trend which should be avoided, namely the trend towards maximal objectivity. That trend is apparent in some of the more highly controlled laboratory studies. It is also apparent in research using a definition of creativity that includes a social requirement. The social requirement is clear when creativity is defined such that only behaviors that have impact are deemed creative. The epitome of this view is probably the "attributional theory of creativity" that appeared in the Creativity Research Journal. Product views are also problematic because they require that there is some manifest result or outcome of the creative process. Admittedly, there are different ways of defining a product. I myself have used ideas as products, at least in some theorizing. My concern over the theories that require social recognition is that they will relegate the personal creativity that is of utmost importance (Runco, 1996, 2006; 2007). Socially recog- 
nized creativity depends on the personal creativity that comes first (Runco, 2006). It is a cause while socially recognition is an effect. Additionally, social theories may not adequately recognize everyday creativity (Richards \& Runco, 1998), children's creative, nor creative potential. It is easy to see that definitions that require any sort of impact or attribution conflate creativity with things which are independent of creativity. I have detailed this conflation elsewhere (Runco, 1995) and hope my concerns about misleading trends are clear so I will move on to the last question.

Izabela Lebuda: You are the one of the most productive creativity psychologists. Can you share your advice, principles of effectiveness in scientific work?

Mark Runco: I hesitate offering advice, but I may be able to describe things that worked for me. I have discovered that many of these are consistent with creativity theory. Take the intrinsic motivation principle (Amabile, 1990; Runco, in press). This is an important concept in the creativity research. It is also recognized outside of creativity theory. Skinner was not studying creativity (and did not believe it could be scientifically studied) when he suggested that when you find something that is interesting, drop everything else and pursue it. And psychologically, you could argue that you can't succeed unless you are pursuing something that is intrinsically motivating.

Another concept in creativity theory is contrarianism (Runco, 1999, 2021). I did not plan to be a contrarian but I have had to ignore advice many times. Because of the high level of intrinsic motivation, I focused on the work, not what I was told was important, and not tenure or promotions. Looking back I was amazingly lucky. I earned tenure at three universities. Because luck played a role, and because of the need for discretion (Runco, 1996), I have often shared the quotation, "dare to be a radical but don't be a damn fool." Indeed, if I were to actually offer advice I would probably say, balance personal interests with practical concerns. That is the suggestion, but that's not what I did. I was not very practical. I was entirely focused on my work on creativity. This led me to a surprisingly useful tactic. This has been labeled satisficing-doing the minimum to get by. If you satisfice, you take the first solution found for a problem rather than investing time to find better solutions. Satisficing is generally considered a poor tactic. After all, it means that you are not considering varied options. Yet it may be bad only when the task or problem is bad. Some things are worth your time. Many things suggested by others aren't worth your time. In this light there are tasks where satisficing is the way to go. Get those things out of the way and focus on the intrinsically motivating things that will take you somewhere. I often satisficed to free up time for my work on creativity.

I sometimes wondered if I was out of whack in the sense of doing too much editing. I founded the Creativity Research Journal and edited it for 30 years. When you edit 
too much, you have less time for your own work. On the other hand, editing good material teaches you many things. I always felt that editing the CRJ kept me at the forefront of research. I saw things before they were even published. Sure, some of it was not published, but seeing the wide range of research helped to keep me open-minded. For this reason I always suggest that my $\mathrm{PhD}$ students grab editing experiences when they can. Stay open to new, even wacky and divergent ideas. I will also say that there is much value in Sid Parnes' idea of "let it happen" tactics. These are distinct from effortful "make it happen tactics." Let it happen tactics may be difficult in that you may not feel like you are putting enough effort to the task at hand, but they pay off. So take a walk, like Piaget (it was one of his daily tactics, mid-day) or a nap, or do something off task for a while. This reminds me that I was once on a panel about writing and each of us was asked to talk about writer's block. I went last and everyone else described their experiences with writer's block. I was the only one who said that it was never a problem. If I run into a problem with writing, I put that project aside and turn to something else. This allows me to keep working. I have never felt blocked because I am always working on something, even if I must jump from one project to another once in a while. Here again luck played a role because I was following intrinsically motivated projects, which generally have no deadlines. No one was pushing me or waiting on me to finish any one of them. Jumping from project to project was not a problem. It may have helped in the sense of cross fertilization. The idea of intrinsic motivation again applies in that it helps a person to find projects where work is not really work and where creative insight is likely. If you are intrinsically motivated, you care about the end result but also enjoy the journey. That is really a good place to end because it is such a wonderful idea: enjoy the journey.

\section{REFERENCES}

Amabile, T. M. (1990). Within you, without you: The social psychology of creativity, and beyond. In M. A. Runco \& R. S. Albert (Eds.), Theories of creativity (pp. 61-91). Newbury Park, CA: Sage.

Bruner, J. (1962). The conditions of creativity. In J. Bruner (Ed.), On knowing: Essays for the left hand. Cambridge, MA: Harvard University Press.

Piaget, J. (1976). To understand is to invent. New York: Penguin.

Runco, M. A., \& Richards, R. (Eds.). (1998). Eminent creativity, everyday creativity, and health. Norwood, NJ: Ablex.

Runco, M. A. (1995). Insight for creativity, expression for impact. Creativity Research Journal, 8, 377-390. https://doi.org/10.1207/s15326934crj0804_4 
Runco, M. A. (1996). Personal creativity: Definition and developmental issues. New Directions for Child Development, No. 72 (Summer), pp. 3-30.

Runco, M. A. (1999). Contrarianism and creativity. In M. A. Runco \& S. Pritzker (Eds.), Encyclopedia of creativity (pp. 367-371). San Diego, CA: Academic Press.

Runco, M. A. (2006). Creativity is always personal and only sometimes social. In J.Schaler (Ed.), Howard Gardner under fire: The rebel psychologist faces his critics (pp. 169-182). Chicago: Open Court Publishers.

Runco, M. A. (2007). To understand is to create: An epistemological perspective on human nature and personal creativity. In R. Richards (Ed.), Everyday creativity and new views of human nature: Psychological, social, and spiritual perspectives (pp. 91-108). Washington, DC: American Psychological Association.

Runco, M. A (2021). Contrarian's Apology and the Changing Contexts of Creativity Research. In D. Dai \& R. J. Sternberg (Ed.), Scientific Inquiry into Human Potential: Historical and Contemporary Perspectives Across Disciplines (pp. 126-141). New York: Routledge.

Runco, M. A. (in press). A hobby out of control: Festschrift for Teresa Amabile. In R. Reiter-Palmon (Eds.), Festschrift for Teresa Amabile. New York: Springer.

Corresponding author at: Izabela Lebuda, Uniwersity of Wroclaw, 1 Dawida St., 50527 Wroclaw, Poland.

E-mail: izabela.lebuda@uwr.edu.pl 